\title{
Magnetotelluric study of the Xuefeng mountain area, Hu'nan Province, China
}

\author{
Musen Chen $\cdot$ Lingxiang Xue $\cdot$ Yousheng Wang $\cdot$ Shengjun Zhu
}

Received: 24 September 2015/ Accepted: 7 January 2016/Published online: 26 March 2016

(C) The Author(s) 2016. This article is published with open access at Springerlink.com

\begin{abstract}
A magnetotelluric study was carried out in the Xuefeng mountain uplift belt and its western margins. A detailed investigation was made of the resistivity of the formations, and reliable data were obtained. The sedimentary cover and basement structure of the Xuefeng mountain area and the deep geological structure were analyzed in detail using magnetotelluric data from the twodimensional inversion of the resistivity profile data in combination with regional gravity and magnetic data. It was concluded that the tectonic movements were characterized by basement detachment, and north-south ramp. The study area can be divided into a southern uplift zone, a southern thrust-faulted zone, a central uplift zone, and a northern depression zone. This work has provided geophysical evidence that can be used in future studies of the tectonics and petroleum geology of this region.
\end{abstract}

Keywords Magnetotelluric study - Resistivity measurements · Basement detachment · Integrated geological and geophysical interpretation

\section{Introduction}

The Xuefeng mountain uplift belt is located in the west of Hu'nan Province, China. The mountains are NE-trending and are nearly $100 \mathrm{~km}$ wide, stretching for hundreds of kilometers. The Neoproterozoic Banxi Group is exposed over a large area at the base of the structural belt and the reason for the exposure of these basement rocks is one of

M. Chen $\cdot$ L. Xue $(\bowtie) \cdot$ Y. Wang $\cdot$ S. Zhu

Sinopec Geophysical Corporation Jianghan Branch,

Qianjiang 433199, China

e-mail: 306820867@qq.com the core problems in the tectonic analysis of the south China region. There have been a number of different geological interpretations of the geotectonic nature of the Xuefeng mountain area, although the consensus is that this area is an important geological boundary.

It has previously been suggested that the Precambrian metamorphic rocks outcropping in south China are an in situ series representing the long-term tectonic uplift of part of the so-called Jiangnan Ancient Land (Huang et al. 1977). An alternative view is that the Proterozoic Banxi Group exposed in this area is a nappe formed by large-scale overthrusting as a result of plate collision (Xu 1980, 1987; $\mathrm{Xu}$ et al. 1987). During the Caledonian, the Xuefeng mountain area experienced many phases of epicontinental and intracontinental orogeny, which resulted in the development of folding similar to that in the Jura mountains and a quasi in situ imbricated thrust nappe structure. Qiu et al. (1999) suggested that the exposed Proterozoic Banxi Group is the result of this thrust nappe tectonic setting and not an Appalachian-style remote long-distance nappe. Other researchers (Chen et al. 2001; Yan et al. 2000) have proposed that the principal part of the Xuefeng mountain tectonic belt is the result of the SE to NE movement of a large-scale thrust nappe, arguing that the local development of a NW to SE reverse fault represents a reverse thrust fault sandwiched between two detachment faults, or is the result of late shallow tectonic superposition. However, Zhu (1983) proposed that the Xuefeng mountain thrust structural belt is a two-way ramp structure dominated by a SE-thrusting action.

A lack of deep geophysical data and understanding of the styles of tectonic deformation in this area have resulted in these widely diverging views of the geological history. We therefore carried out a magnetotelluric (MT) survey 
through the Xuefeng mountain uplift belt and its western margin (Fig. 1). By combining these data with related geological and geophysical information, the development and location of the thrust nappe belt and its deep tectonic characteristics can be explained. This study provided geophysical evidence that could be used in further studies of the tectonics and petroleum geology of the region.

\section{Regional geological survey}

The Xuefeng mountain tectonic belt is located in the center of the continental upper Yangtze block in southern China and is also referred to as the Xuefeng mountain intracontinental tectonic system. The division of the tectonic units in this area is as follows: the Hu'nan-Guangxi intracontinental tectonic belt lies west of the ChenzhouLinwu fault and east of the Anhua-Xupu fault; the Xuefeng mountain basement uplift belt lies west of the Anhua-Xupu fault and east of the Cili-Baojing fault; and the Xuefeng mountain western margin extended band lies west of the Cili-Baojing fault and east of the HefengLaifeng fault (Wang and Yan 2011; Li et al. 2011).

The Xuefeng mountain area has experienced multiple phases of tectonic movement and formed multiple unconformities. Movement during the formation of the Wuling mountain uplifted and denudated the basement rocks and locally preserved the angular unconformity. During the Jinning tectonic movements, the area was uplifted in the north and depressed to the south. After the Sinian period, the Xuefeng area entered into a new stage of tensile fracturing. During the late Caledonian orogeny, the Sinian to Silurian rocks was involved in strong extensional tectonic movements. Tensile fracturing occurred again in south China in Devonian to Triassic times, accompanied by transgression and the deposition of thick marine carbonates. Since the late Triassic, different areas have suffered strong nappe thrusting, resulting in uplift of the basement rocks. Seawater gradually withdrew from the area and the region eventually became a terrestrial sedimentary environment.

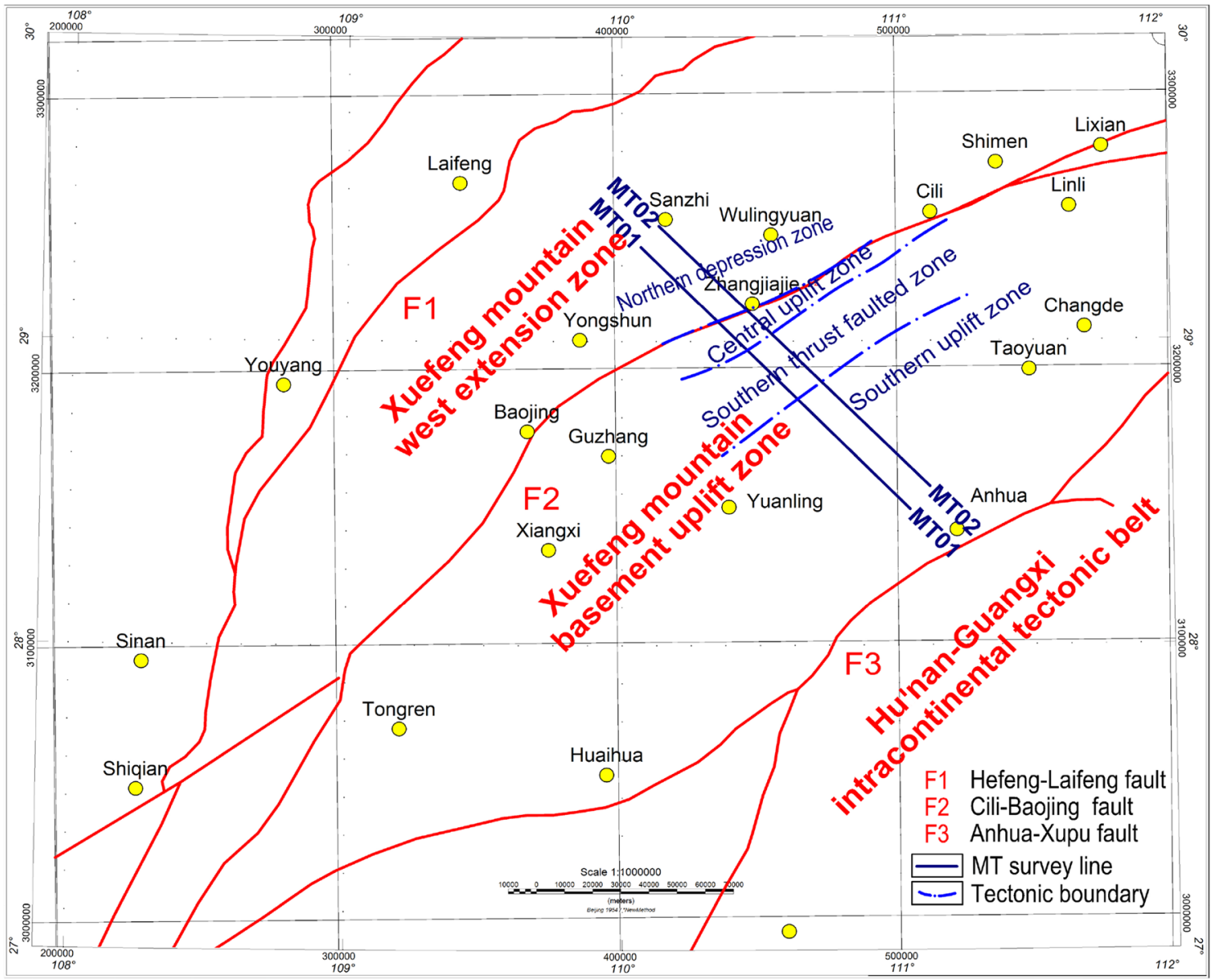

Fig. 1 Study area showing the location of the measuring line and the configuration partition map 


\section{Regional geophysical survey}

In the Sangzhi-Cili-Yuanling region, the overall gravity field presents as NW-SE-trending and there is a high gravity anomaly in the vicinity of the Cili-Yuanling fault zone, which gradually reduces toward Sangzhi. The maximum anomaly is $-8 \mathrm{mGal}$ and the minimum is $-105 \mathrm{mGal}$. The rock density in the Paleozoic sediments is generally less than that in the Proterozoic strata and the variation in the gravity field reflects the variation in thickness of the sedimentary cover (Paleozoic). Based on the changes in the gravity field in this area, the thickness of the sedimentary strata in this area gradually deepens from SE to NW. Along the Cili-Zhangjiajie line there is a gradient in the gravity field, which is the boundary between the area of uplift and the area that has been lowered. Combined with the analysis of the geological maps, this gravity gradient can be shown to be located in the CiliZhangjiajie fault zone and is one of the most important geological boundaries in this area (Fig. 2).

The magnetic anomaly in this area changes smoothly from +20 to $-20 \mathrm{nT}$ and the overall trend is a gradual decrease from SE to NW. The magnetic field north of Zhangjiajie is about $-20 \mathrm{nT}$ and is very stable, reflecting the characteristics of the thick sedimentary strata in this area. The magnetic field is relatively high south of Zhangiajie and reflects the relative uplift of the Proterozoic basement (Fig. 3).

Regional gravity and magnetic data provide a good basis for the analysis of the tectonic general trend and the thickness variation of the regional stratigraphic.

\section{Acquisition of field data}

A V5-2000 (MTU-2A, MTU-5A) instrument was used to collect the field data. The acquisition frequency range was $320-0.001 \mathrm{~Hz}$ and the field acquisition time record was $>12 \mathrm{~h}$. The data were processed to reduce the effects of human interference and to provide reference data. The GPS post-difference method was used to determine the point position. The dot pitches of the MT data and the border were set to 1000 and $500 \mathrm{~m}$, respectively. The small dot pitch of the MT data allowed us to study the detailed structure of the area.

\section{Acquisition and analysis of rock electrical data}

Rock resistivity distribution characteristics are the important basis to divide strata electrical layer. We conducted a detailed study of the rock resistivity and its distribution in this region.

The resistivity of the rocks was determined using a Chongqing Geological Instrument Factory DDC-6 electronic automatic compensation device. The quadrupole vertical electrical sounding method was used to measure the formation resistivity with observation parameters of $A B / 2=25-35 \mathrm{~m}$ and $M N / 2=3 \mathrm{~m}$. The point position was determined using GPS navigation and the field data included the point position, the stratigraphic chronology, the lithology, and the resistivity value.

We collected data from a total of 12 strata, with about 30 sampling points in each stratum. Using the symmetrical quadrupole field data, the resistivity data were classified based on the stratigraphic units.

Changes in the resistivity of a formation are closely related to the lithology, which, in turn, is closely related to the tectonic sedimentary environment. The variation information resistivity was compared with the different tectonic layers and a correspondence was found (Fig. 4). The changes in resistivity roughly corresponded to the following four layers.

(1) The Wuling-Xuefeng tectonic layer and the corresponding Sinian strata $(\mathrm{Z})$, the Banxi Group $\left(\mathrm{Pt}_{3}\right)$, and the Lengjiaxi Group $\left(\mathrm{Pt}_{2}\right)$, which belong to a relatively ancient formation with a high resistivity.

(2) The Caledonian tectonic layer, with the corresponding Cambrian $(\in)$, Ordovician $(\mathrm{O})$, and Silurian (S) strata, which exhibit a low $\left(\epsilon_{1}\right)$-high-low (S) resistivity.

(3) The Hercynian-Indosinian tectonic layer with corresponding Devonian (D), Permian (P), and Triassic $\left(\mathrm{T}_{1}\right)$ strata. The resistivity of the formation is high (883-1632 $\Omega \mathrm{m})$. After the Caledonian orogeny, Hu'nan Province entered a stable depositional phase characterized by shallow seas; limestone and chertbased giant sedimentary cycles formed during the Devonian to middle Triassic transgressive-regressive phase. The high resistivity reflects the stratigraphic features of this period.

(4) In the Yanshan tectonic layer with corresponding Triassic $\left(\mathrm{T}_{2}\right)$ and Cretaceous $(\mathrm{K})$ strata, the formation resistivity is low $(<100 \Omega \mathrm{m})$. The structural unconformity overlies the Hercynian-Indosinian layer. The sediments are continental deposits.

Three low resistivity layers $\left(K-T_{2}, S, \epsilon_{1}\right)$ are present in the area and are separated by the high resistivity $\mathrm{T}_{1}, \mathrm{P}$, $\mathrm{O}$, and $\epsilon_{2+3}$ layers. The Precambrian basement strata are represented by layers of high resistivity. The distribution of the formation resistivity provides a reliable basis for the interpretation of electromagnetic data. 


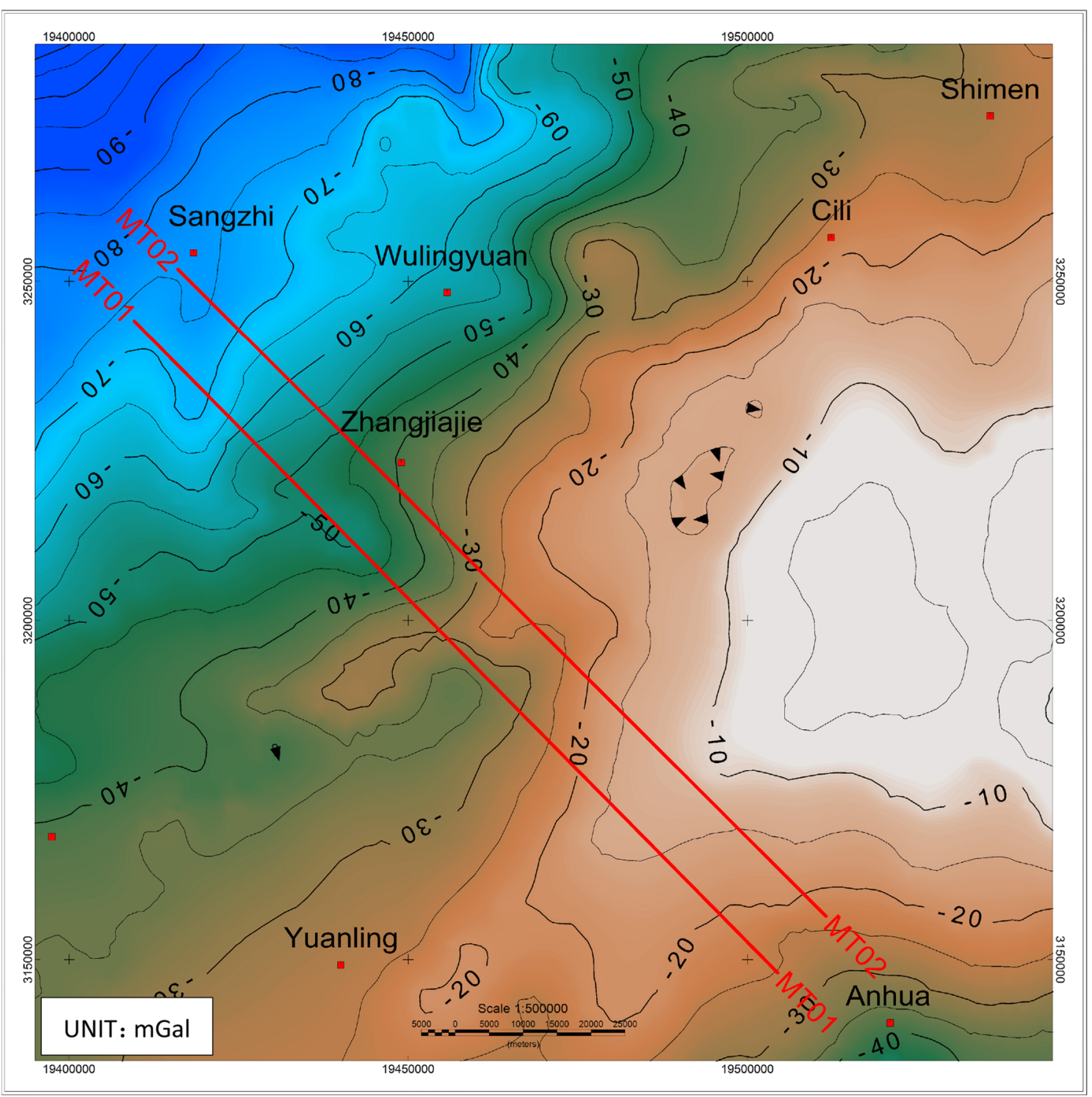

Fig. 2 Bouguer gravity anomaly map (internal data)

\section{Data processing and interpretation}

\subsection{Processing and interpretation process}

Figure 5 is a flow diagram of the steps used in the processing and interpretation of the obtained data. After preprocessing and qualitative analysis and the smoothing and correction of the data, one- and two-dimensional inversions were carried out. Integrated interpretation and analysis were performed in combination with geological and other geophysical data.

According to the planar distribution characteristics of the gravity and magnetic data, the region's overall structure is NE-trending, which in the same direction with the surveying line. The positive direction used in the construction was magnetic north. Based on the structural characteristics of the area, NE was selected as the electrical spindle direction and all the measuring points were rotated by $45^{\circ}$.

Adjacent points were used for curve smoothing and compared with the smooth way and D+ smoothing methods. Adjacent points were compared and the surface formation actual resistivity contrast method was used for static correction.

A nonlinear conjugate gradient inversion method was used to obtain the two-dimensional resistivity inversion. The achievement profiles were based on the results of the joint inversion of apparent resistivity and phase data on the two directions of TE and TM. 


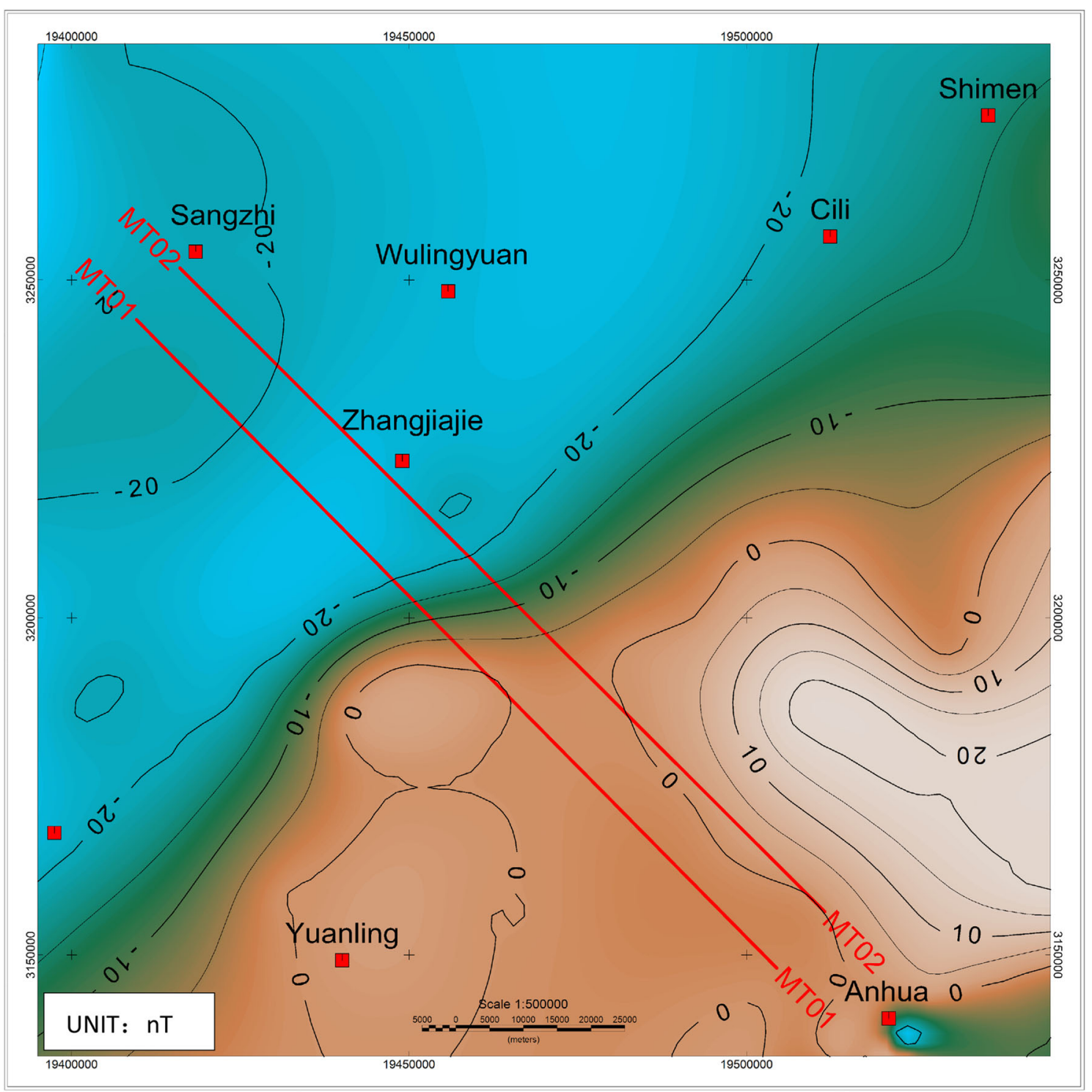

Fig. 3 Magnetic $(\Delta T)$ contour map (internal data)

\subsection{The qualitative analysis}

Draw the line frequency-apparent resistivity and phase contour map with the electromagnetic data after rotation, smooth, and correction (Figs. 6, 7, 8, 9). According to the contour change law of the frequency-apparent resistivity and phase, it is clear that the apparent resistivity can be divided into four zones, the southern high resistivity zone, the central low resistivity zone, the central high resistivity zone, and the northern low resistivity zone.

In the southern high resistivity zone, the resistivity is high overall, and $\rho_{\mathrm{xy}}$ is characterized by KHK type, as shown in point 1020 of line MT01 in Fig. 10.

In the central low resistivity zone, upper and lower resistivity layers obviously, the upper is high resistivity and the lower is low resistivity. $\rho_{\mathrm{xy}}$ is characterized by KQQ type, as shown point 1560 of line MT01 in Fig. 10.

In the central high resistivity zone, a larger difference between the two curves. $\rho_{\mathrm{xy}}$ is characterized by AK type, as shown in point 1810 of line MT01 in Fig. 10.

In the northern low resistivity zone, the resistivity is low overall, and changes smoothly. $\rho_{\mathrm{xy}}$ is characterized by HKHK type, as shown in point 2330 of line MT01 in Fig. 10.

\subsection{Integrated geological and geophysical interpretation}

Based on recent geological investigations, the fractures in the Xuefeng Mountain area are mainly thrust faults and strike-slip faults. 


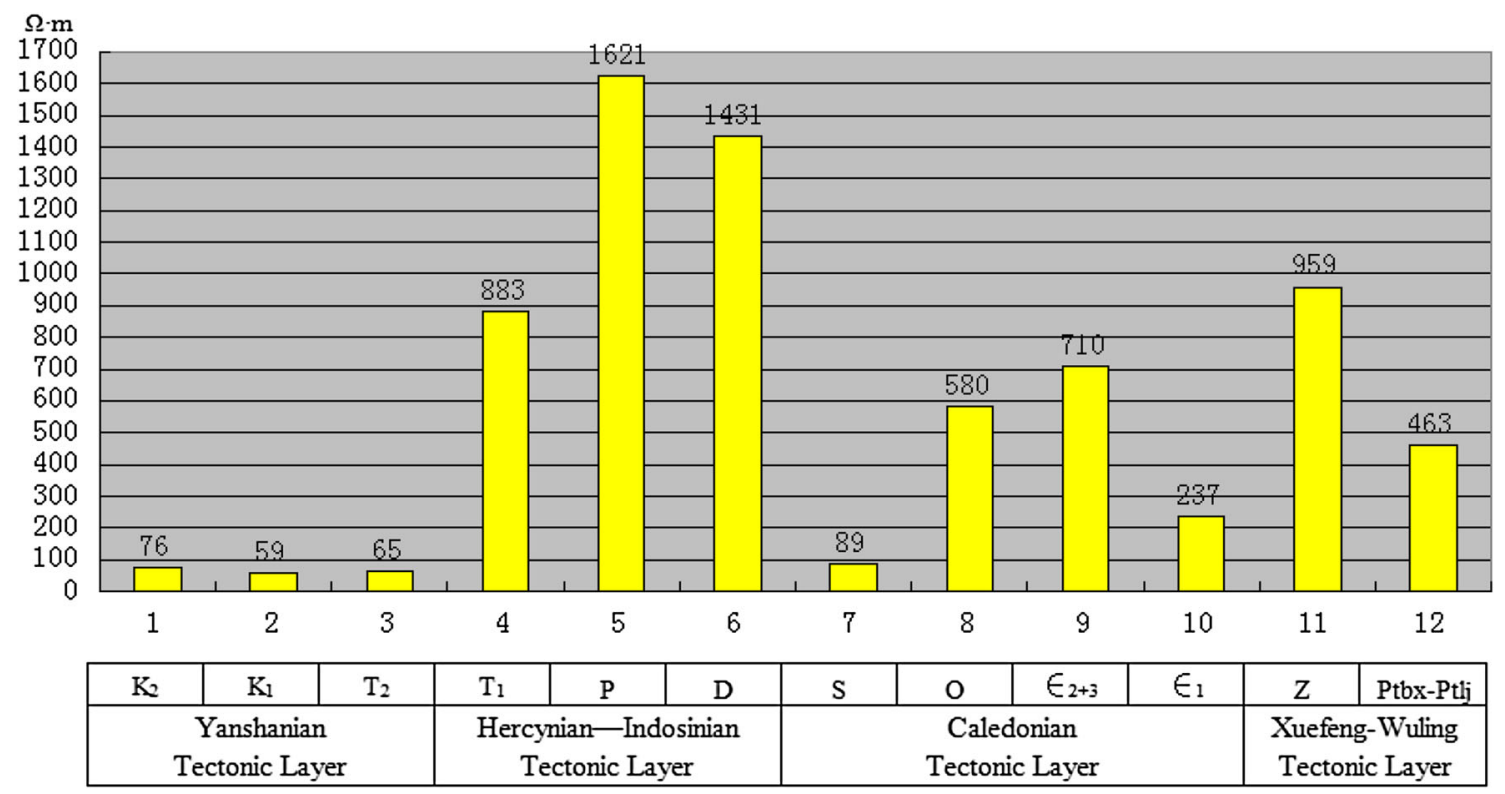

Fig. 4 Correspondence between formation resistivity and structural layers

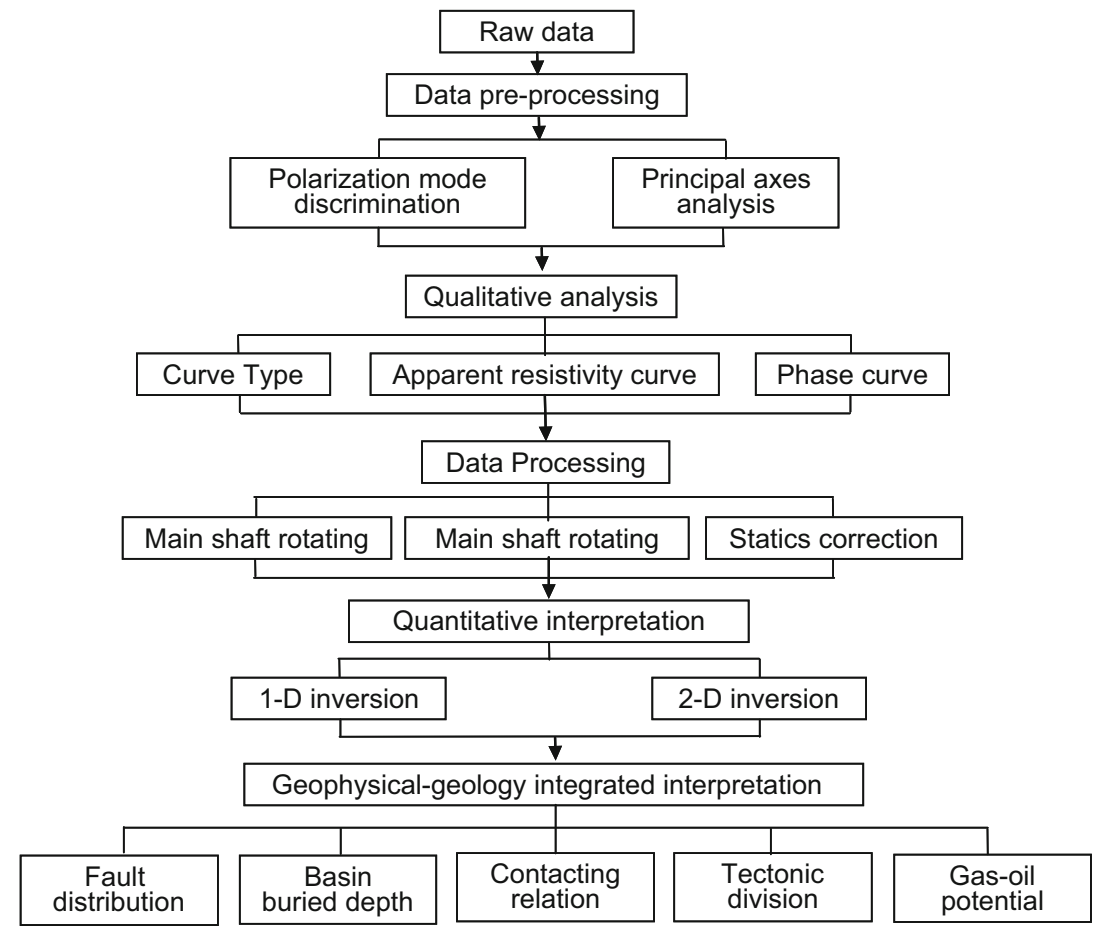

Fig. 5 Processing and interpretation of magnetotelluric data

The Xuefeng basement was gradually uplifted in the late Triassic. It is a thick-skinned thrust nappe in which basement detachment occurred from south to north and SE to NW. The thrusting action of the nappe has resulted in the Mesozoic-Paleozoic marine facies on the Yangtze block showing progressively strong to weak deformation structures (attenuation) from SE to NW.
There are at least two layers of slippage at shallow and deep levels in the Xuefeng mountain area. Within the central Hu'nan structural belt a shallow slip layer is divided into two: one layer along the Devonian imbricate thrust to the west and the other along the top of the Upper Banxi Group, where its branches cut through Paleozoic strata. 


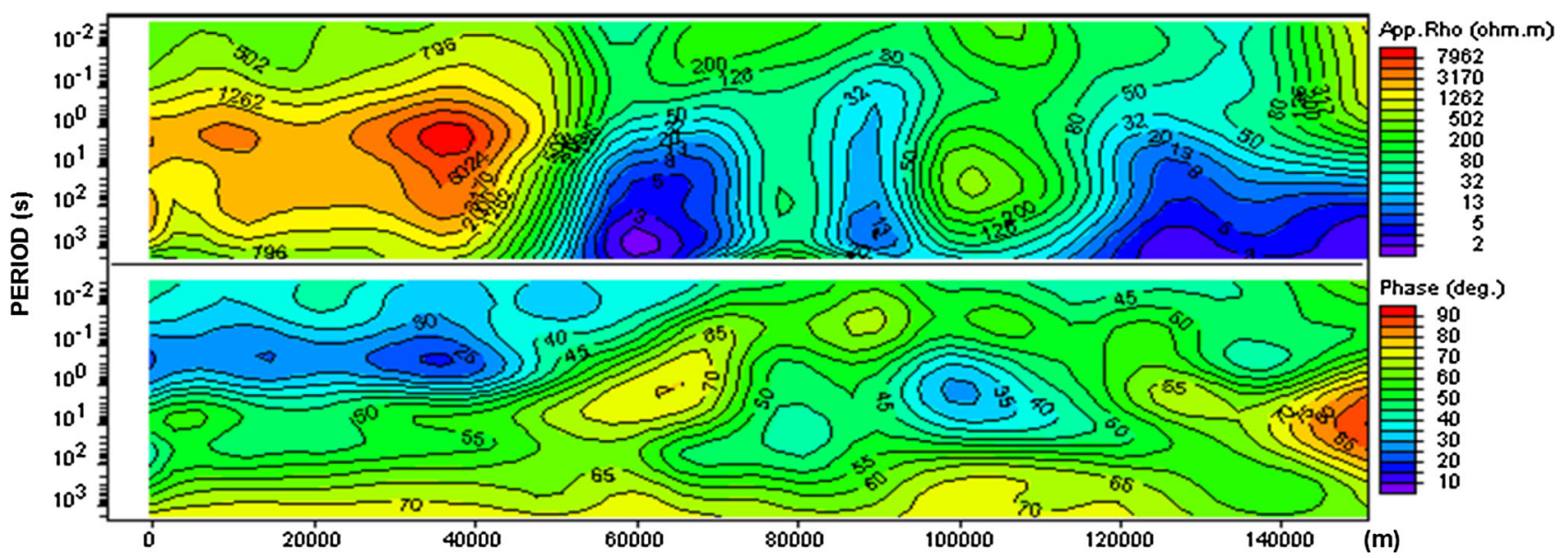

Fig. 6 Line MT01 frequency-apparent resistivity and phase contour map (TE)

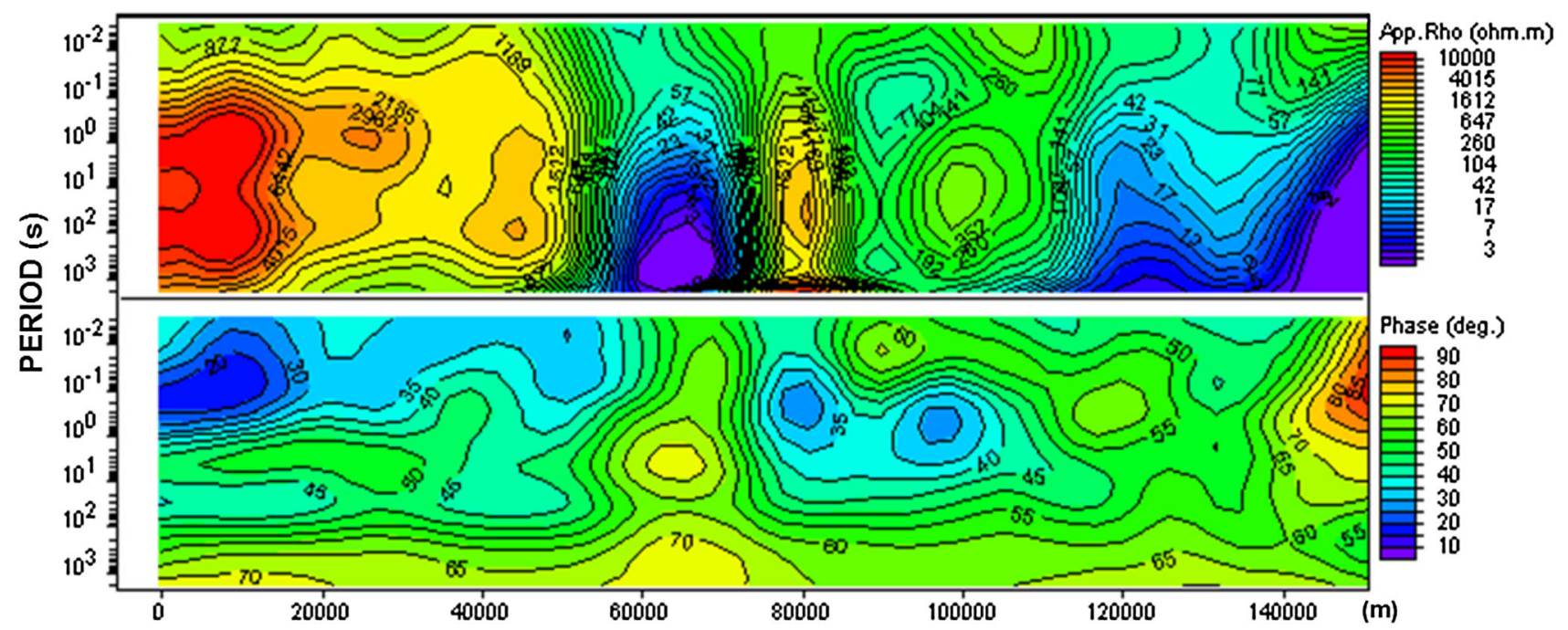

Fig. 7 Line MT01 frequency-apparent resistivity and phase contour map (TM)

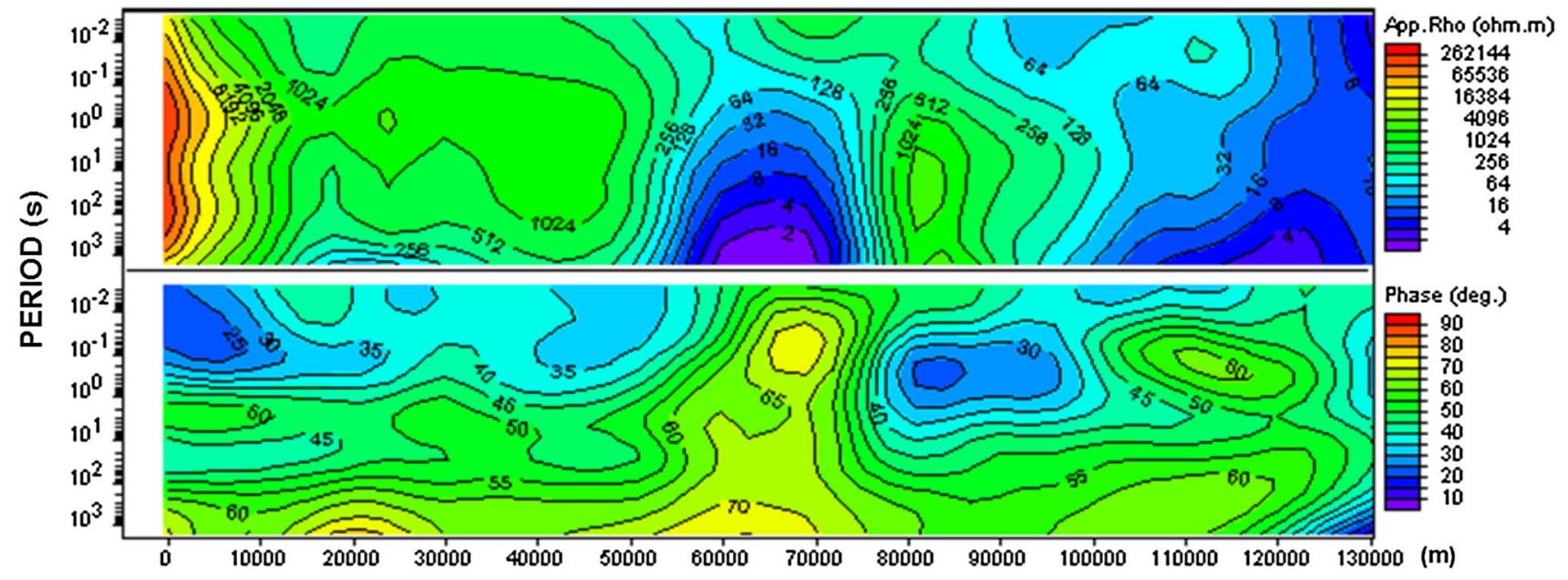

Fig. 8 Line MT02 frequency-apparent resistivity and phase contour map (TE) 


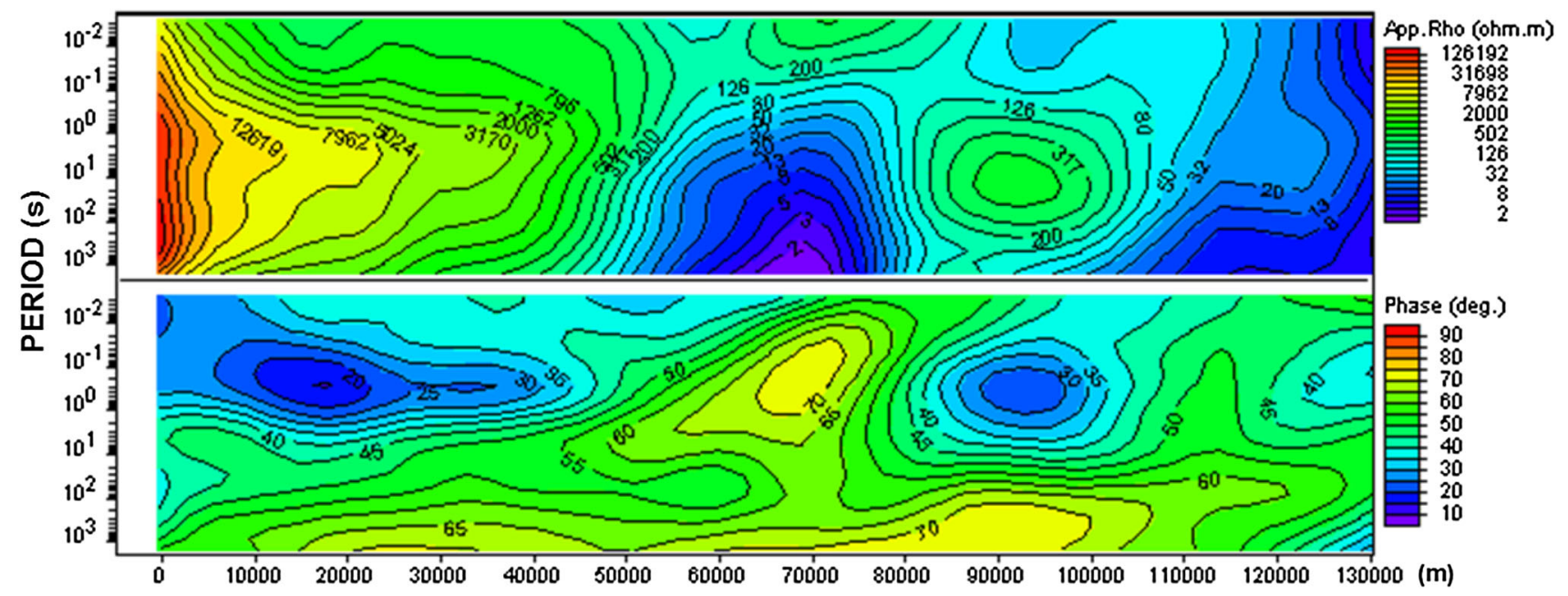

Fig. 9 Line MT02 frequency-apparent resistivity and phase contour map (TM)

The Upper Banxi Group interface is a deep slip surface with SE-NW-thrusting through the central Hu'nan structural belt and the tectonic belt in the Xuefeng mountain area, which uplifted the basement rocks. The dip is gently to the SE. The thrust reaches the surface in the Zhangjiajie area and is related to the Cili-Baojing fault zone, exposing Sinian rocks and the Upper Banxi Group. The western margin of the Xuefeng tectonic belt has a deep slip layer trending toward the NW, mainly in Cambrian rocks. The top of the slip surface has a relatively gentle slope, but the bottom is steep and cuts through Ordovician and Silurian rocks before reaching the surface; this deep slip layer and the deep slip layer on the SE form a ramp structural pattern (Li et al. 2011).

The formation properties were determined on the basis of the gravity, magnetic, and seismic data collected in the area, together with the two-dimensional MT inversion profile. The analysis of the electrical resistivity, density, and magnetic data was considered with reference to the geological data. A comprehensive analysis of the plane and section data was used to explain the stratigraphic thickness, the burial depth, and the distribution of fractures in the study area.

The geological strata were divided on the basis of the two-dimensional resistivity structure of the profile. The structural partition was based on the stratigraphic divisions and the distribution of fractures in each section (Fig. 1). The working area was divided into four tectonic zones: the southern uplift zone; the southern thrust-faulted zone; the central uplift zone; and the northern depression zone. The following sections describe the interpretation of the results for each profile.

\subsubsection{Integrated interpretation of line MTO1 profile}

Line MT01 is $145 \mathrm{~km}$ long and crosses the southern uplift zone, the southern thrust-faulted zone, the central uplift zone, and the northern depression zone (Fig. 11).

The southern uplift zone lies between 0 and $55 \mathrm{~km}$ on the profile and the main formation resistivity is $>10,000 \Omega \mathrm{m}$. The Proterozoic Banxi $\left(\mathrm{Pt}_{3}\right)$ and Lengjiaxi groups $\left(\mathrm{Pt}_{2}\right)$ are exposed and the low resistivity Cretaceous (K) formation is locally distributed.

The southern thrust-faulted zone lies between 55 and $75 \mathrm{~km}$ on the profile. The resistivity is high in the upper strata $(>1000 \Omega \mathrm{m})$ and there is a low resistivity $(2-50 \Omega \mathrm{m})$ region between 3000 and $10,000 \mathrm{~m}$ depth. Based on the surface geology and the resistivity results, the overlying strata are suggested to be Ordovician (O) to upper to middle Cambrian $\left(\epsilon_{2+3}\right)$, and the underlying low resistivity body is suggested to be of Cambrian $\left(\epsilon_{1}\right)$ age. The area is an overthrust belt, and the thrust face is within lower Cambrian strata.

The central uplift zone lies between 75 and $105 \mathrm{~km}$ along the profile, and the resistivity changes from high to low from top to bottom. The high resistivity of the overlying strata suggests that they are Ordovician to upper or middle Cambrian; the low resistivity strata are Cambrian. The main feature of the area is the uplifted high resistivity basement; the depth of the high resistivity body is between 2000 and $3000 \mathrm{~m}$.

The northern depression zone lies between 105 and $145 \mathrm{~km}$ along the profile and the low resistivity zone gradually deepens from south to north. The thickness of the sedimentary cover increases gradually from south to north. 

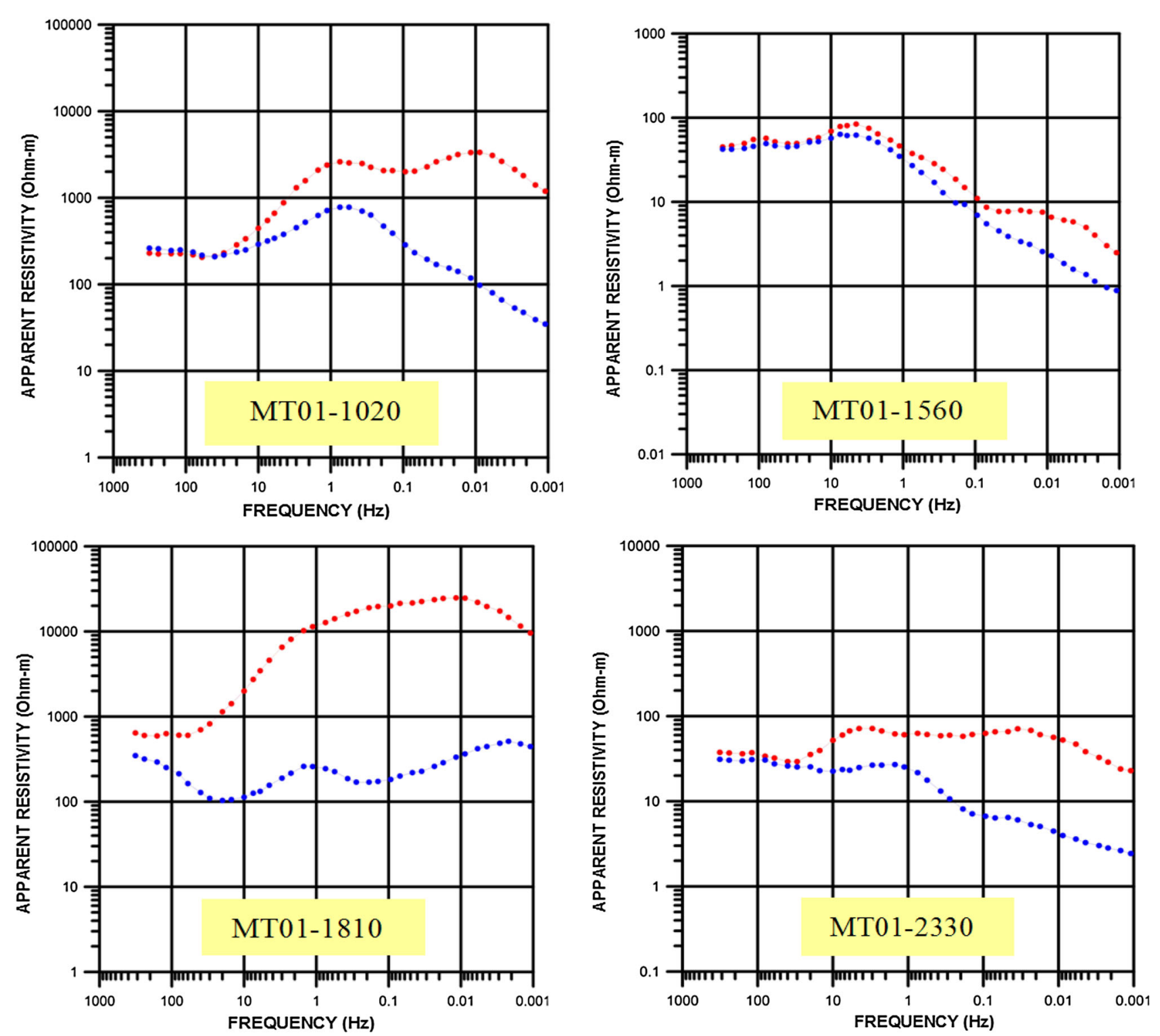

Fig. 10 Typical curves of magnetotelluric sounding in the work area ( red $\rho_{\mathrm{xy}}$, blue $\left.\rho_{\mathrm{yx}}\right)$

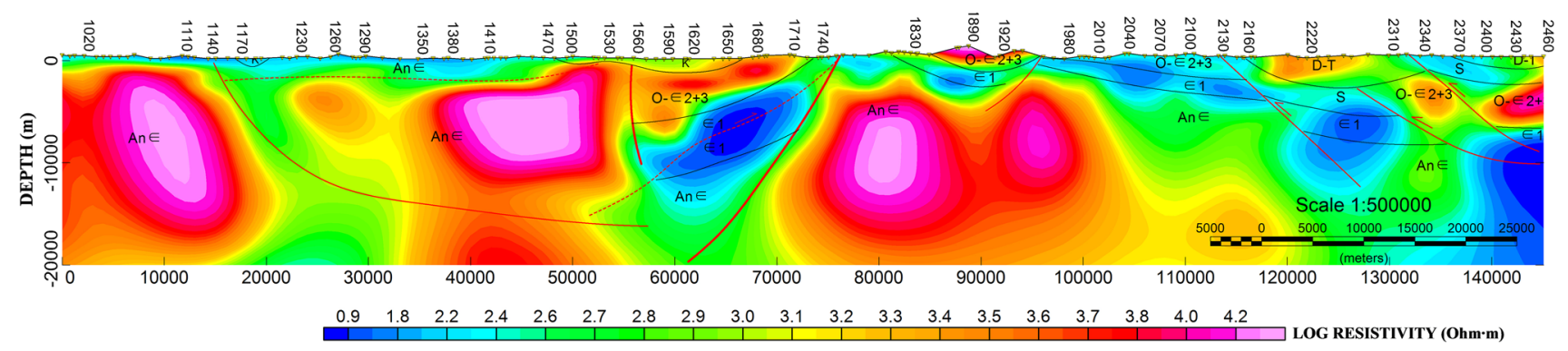

Fig. 11 Sangzhi-Shimen area MT01 resistivity inversion and integrated geological interpretation

Based on the exposed strata and variations in ground resistivity, it is suggested that the distribution, from top to bottom, is Devonian (D)-Permian (P) strata (high resistivity layer), Silurian strata (S) (low resistivity layer), Ordovician to upper or middle Cambrian (high resistivity level), and Cambrian (low resistivity layer). 


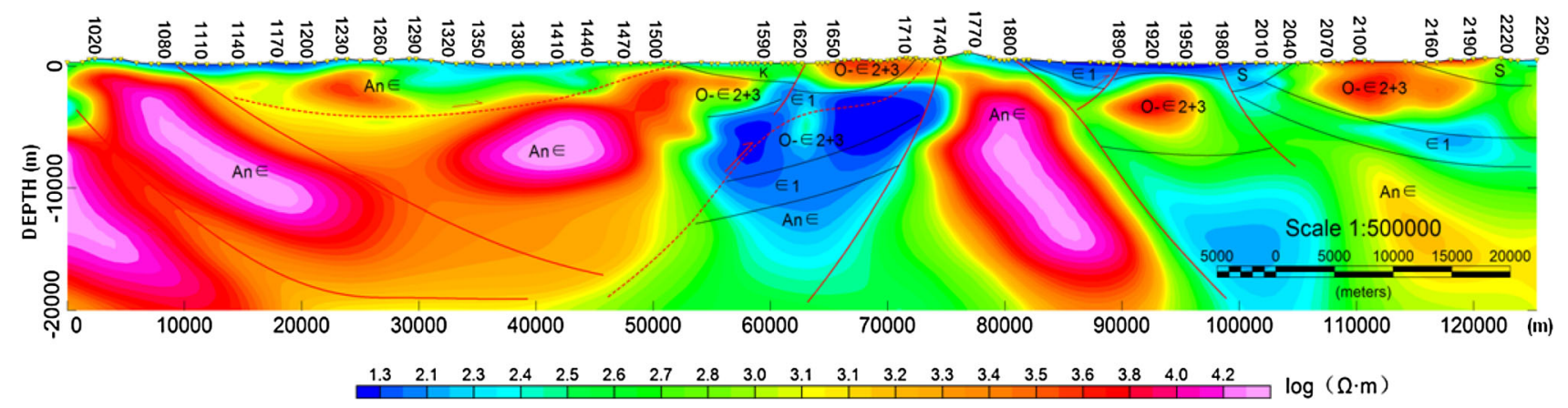

Fig. 12 Sangzhi-Shimen area MT02 resistivity inversion and integrated geological interpretation

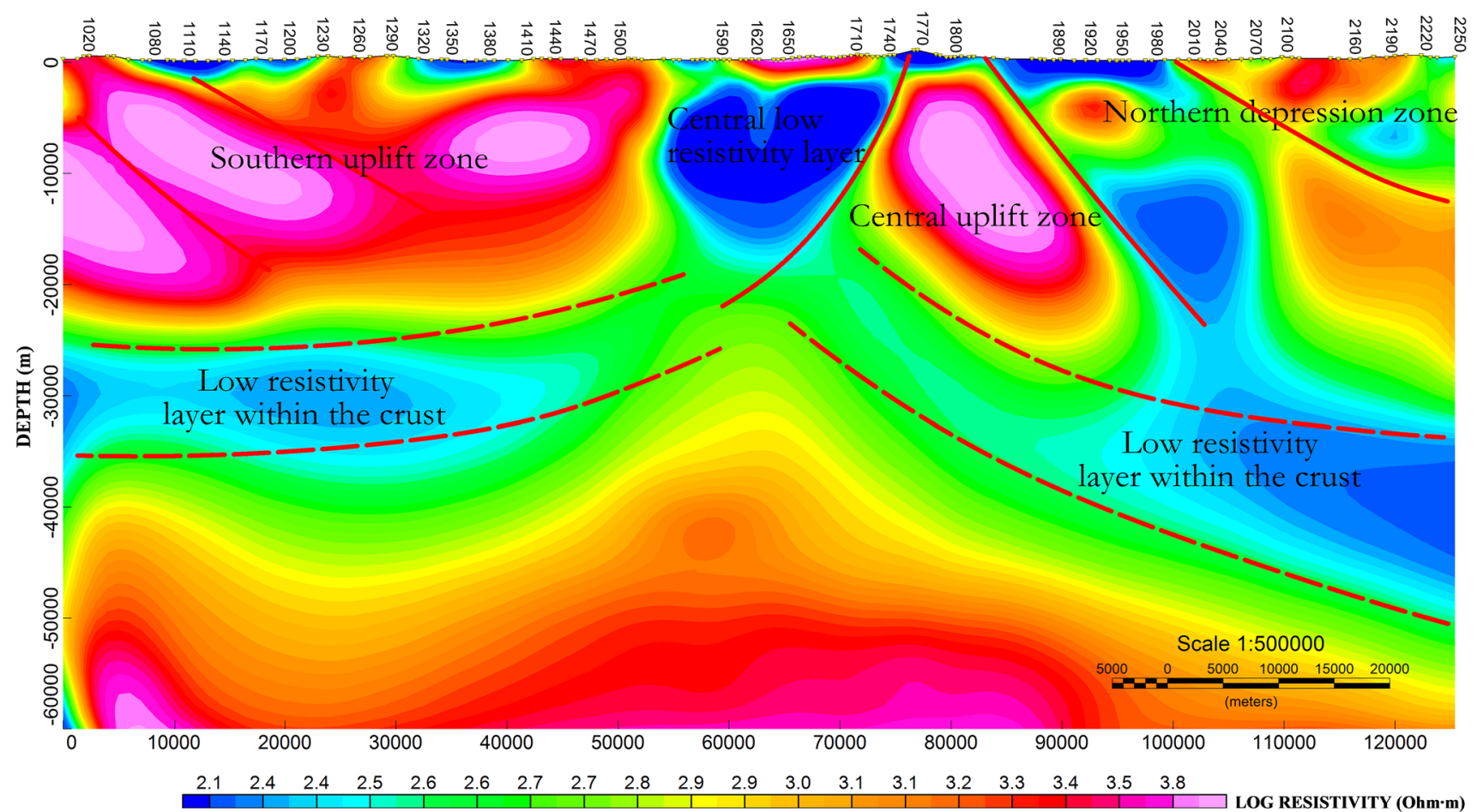

Fig. 13 Line MT02 at $60 \mathrm{~km}$ depth: electrical resistivity results $(1 \mathrm{~km} \times 1 \mathrm{~km}$ grid $)$

\subsubsection{Integrated interpretation of line MT02 profile}

Line MT02 is $125 \mathrm{~km}$ long with similar profiles for the strata and fracture structures to those of line MT01 (Fig. 12).

The southern uplift zone lies between 0 and $55 \mathrm{~km}$ along the profile, and the high resistivity layer is suggested to represent Precambrian strata.

The southern thrust-faulted zone lies between 55 and $75 \mathrm{~km}$ along the profile. The upper layer has a high resistivity and it is suggested that the overlying strata are Ordovician to upper Cambrian rocks and that the underlying low resistivity body consists of Cambrian strata.

The central uplift zone lies between 75 and $90 \mathrm{~km}$ along the profile and is a high resistivity body with a slope to the north. The resistivity is $>10,000 \Omega \mathrm{m}$.
The northern depression zone lies between 90 and $125 \mathrm{~km}$ along the profile, and the sedimentary cover gradually deepens from the south to the north. The high resistivity strata are Ordovician to middle or upper Cambrian rocks, and the low resistivity strata are Silurian to Cambrian.

\subsubsection{Analysis of the deep electrical structure}

The electrical structure of the Earth's crust to a depth of $20 \mathrm{~km}$ shows detachment of the Precambrian basement. Using the central uplift zone as a pivot, a structural pattern of north-south ramp is formed.

The electrical section along the MT02 line at $60 \mathrm{~km}$ depth (Fig. 13) shows the following features. At $25-35 \mathrm{~km}$ depth, there is an obvious low resistivity layer connected 
with the surface fault. This low resistivity layer may be a slip plane related to tectonic movement and the uplift or sinking of deep material. The surface structure of the Earth's crust may have developed tensile fracturing or squeeze thrusts, forming an overall tectonic framework of north-south ramp along the axis of the central uplift zone.

\section{Conclusion and recommendation}

(1) There are two obvious low resistivity layers in the Mesozoic-Paleozoic strata in Silurian and Cambrian rocks. The high conductivity layer in the crust is found between 25 and $35 \mathrm{~km}$ and the distribution of this high conductivity layer controls the tectonic style of the basin. The resistivity profiles show basement detachment and the tectonic framework of the northsouth ramp.

(2) Based on the electrical characteristics of the formations in this area, it can be divided into four tectonic units, namely, the southern uplift zone, the southern thrust-faulted zone, the central uplift zone, and the northern depression zone.

(3) Low resistivity Cambrian strata are present in the southern thrust-faulted zone, the central uplift zone, and the northern depression zone. There Paleozoic strata could be used as targets for oil and gas exploration. However, in terms of the geological structure, the hydrogeological conditions, and the stability of the strata (Ma et al. 2006), the preferred target area is the northern depression zone north of the Cili-Zhangjiajie fault.

Apparent electrical differences exist between layers of Mesozoic-Paleozoic in marine strata in southern China. The Silurian and Cambrian deposits are relatively stable with a typically low resistivity layer that forms the basis of MT exploration. This technology could be applied to oil and gas exploration in the Paleozoic strata after identifying the distribution of the low resistivity formations; this would make subsequent seismic operations more efficient.
Acknowledgments We would like to express ours warmest gratitude to Professor Xiangyun Hu in China University of Geosciences (Wuhan), for his instructive suggestions and valuable comments in the process of the project research.

Open Access This article is distributed under the terms of the Creative Commons Attribution 4.0 International License (http://crea tivecommons.org/licenses/by/4.0/), which permits unrestricted use, distribution, and reproduction in any medium, provided you give appropriate credit to the original author(s) and the source, provide a link to the Creative Commons license, and indicate if changes were made.

\section{References}

Chen G, Yang X, Liang X (2001) A preliminary study of historydynamics in southern China activated region. Geotecton Metal$\log 25(3): 228-238$ (in Chinese with English abstract)

Huang J, Ren J, Jiang C, Zhang Z, Xu Z (1977) China tectonic basic outline. J Geol 51(2):117-135 (in Chinese with English abstract)

Li S, Wang T, Jin C, Dai L, Liu X, Zhou X, Wang Y, Zhang G (2011) The characteristics and causes of the Indosinian period intracontinental in the Xuefeng mountain basement uplift zone and its adjacent areas. Jilin Univ J (Earth Sci Ed) 1:93-105 (in Chinese with English abstract)

Ma Y, Lou Z, Guo T, Fu X, Jin A (2006) To discuss marine facies strata in south China oil and gas preservation conditions integration evaluation technology system. Geol J 80(3):98-109 (in Chinese)

Qiu Y, Zhang Y, Ma W (1999) The structure properties and evolution of the Xuefeng Mountain: the formation of an intracontinental orogenic belt evolution model. Geological Publishing House, Beijing, pp 10-45 (in Chinese)

Wang C, Yan D (2011) Western Xuefeng Mountain Mesozoic thrust nappe tectonic style and deformation characteristics. Mod Geol 25(6):1021-1031 (in Chinese with English abstract)

Xu J (1980) Thin shell type plate tectonic pattern and collision orogeny. Sci China: Ser A 11:1081-1089 (in Chinese with English abstract)

Xu J (1987) There are some tectonic problems in south China. Geol Sci Technol Inf 6(2):13-27 (in Chinese)

Xu J, Sun S, Li J (1987) It is south China orogenic belt rather than south China platform. Sci China: Ser B 10:1107-1115 (in Chinese with English abstract)

Yan D, Wang X, Liu Y (2000) Fold structure style and its formation mechanism analysis in border region of Sichan-Hubei-Hunan. Mod Geol 14(1):37-43 (in Chinese)

Zhu Z (1983) Jura folds in southern China and its formation mechanism. Earth Sci 22(3):45-53 (in Chinese) 